Check for updates

Cite this: RSC Adv., 2021, 11, 39934

\title{
Ligand-enabled and magnesium-activated hydrogenation with earth-abundant cobalt catalysts $\uparrow$
}

\author{
Bo Han, ${ }^{\star}$ Miaomiao Zhang, Hongmei Jiao, Haojie Ma, Jijiang Wang \\ and Yuqi Zhang (D)*
}

Replacing expensive noble metals like $\mathrm{Pt}, \mathrm{Pd}, \mathrm{Ir}, \mathrm{Ru}$, and $\mathrm{Rh}$ with inexpensive earth-abundant metals like cobalt (Co) is attracting wider research interest in catalysis. Cobalt catalysts are now undergoing a renaissance in hydrogenation reactions. Herein, we describe a hydrogenation method for polycyclic aromatic hydrocarbons (PAHs) and olefins with a magnesium-activated earth-abundant Co catalyst. When diketimine was used as a ligand, simple and inexpensive metal salts of $\mathrm{CoBr}_{2}$ in combination with magnesium showed high catalytic activity in the site-selective hydrogenation of challenging PAHs under mild conditions. Co-catalyzed hydrogenation enabled the reduction of two side aromatics of PAHs. A wide range of PAHs can be hydrogenated in a site-selective manner, which provides a cost-effective, clean, and selective strategy to prepare partially reduced polycyclic hydrocarbon motifs that are otherwise difficult to prepare by common methods. The use of well-defined diketimine-ligated Co complexes as precatalysts for selective hydrogenation of PAHs and olefins is also demonstrated.

Received 29th September 2021 Accepted 9th December 2021

DOI: 10.1039/d1ra07266h

rsc.li/rsc-advances
Site selectivity in PAH hydrogenation has long been an important issue. Mixed products are usually formed upon hydrogenation of aromatic scaffolds at different sites, with limited PAH scope. ${ }^{12}$ The use of earth-abundant metals for catalytic hydrogenation of PAHs with site-selective and costeffective method would be of greater value for partially hydrogenated feedstock chemicals synthesis.

In nonprecious-metal-promoted catalysis, an activation strategy involving the reduction of simple, low-cost and commercially available metal salts for in situ formation of active metal catalysts has been established. It offer the advantages of easy handling and potential applications in large-scale

precious metals such as ruthenium, rhodium, palladium, and platinum via heterogeneous catalysis (Scheme 1). ${ }^{11}$ Potassium bis(anthracene)cobaltate has been reported by Jacobi von Wangelin et al. ${ }^{7 a}$ for the hydrogenation reactions of unsaturated molecules (alkenes, arenes, carbonyl compounds). In addition, they have also reported the synthesis of potassium bis $\left(\eta^{4}\right.$ anthracene) metalates of Fe and Co for catalytic hydrogenation of alkenes, ketones and imines at ambient $\mathrm{H}_{2}$ pressure and temperatures. $^{7 i}$

Laboratory of New Energy \& New Function Materials, Shaanxi Key Laboratory of Chemical Reaction Engineering, College of Chemistry and Chemical Engineering, Yan'an University, Yan'an, 716000, P. R. China. E-mail: bhan@yau.edu.cn; yqzhang@iccas.ac.cn

$\dagger$ Electronic supplementary information (ESI) available. CCDC 1840125. For ESI and crystallographic data in CIF or other electronic format see DOI: 10.1039/d1ra07266h

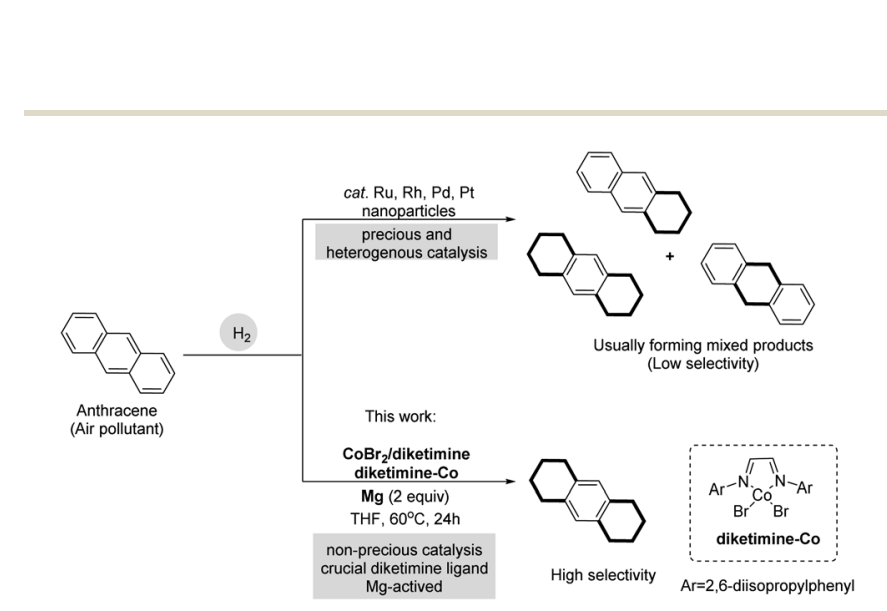

Scheme 1 Transition-metal-catalyzed hydrogenation of $\mathrm{PAH}$ (anthracene). 
manufacturing, with minimal associated hazards in the purification of metal catalysts. ${ }^{13,14}$

We hypothesized whether it will be possible to use earthabundant metal salts as precatalysts to replace expensive metal catalysts, using an in situ activation strategy for achieving the hydrogenation of PAHs with controllable selectivity. Hydrogenation using robust Fe, Co, and Mn catalysts has been reported. However, the hydrogenation of PAHs using these inexpensive metal catalysts has been rather limited. ${ }^{\mathbf{1 5 , 1 6}}$ Zeng's group has developed low-valent cobalt in situ using methylmagnesium bromide as a reducing agent for the hydrogenation of fused PAHs to give two terminal aromatic carbocycles. ${ }^{17}$

Herein, we report a ligand-enabled and magnesiumactivated hydrogenation of PAHs and olefins with in-expensive metal Co catalysis. Site selectivity in the hydrogenation of PAHs can be controlled by these two different, earth-abundant metal catalysts. A combination of $\mathrm{CoBr}_{2}$ and diketimine or a diketimine-ligated Co complex with magnesium as a reductant showed good catalytic activity in the selective hydrogenation of two side aromatics of PAHs (Scheme 1). Preactivation with $\mathrm{Mg}$ was performed by placing $\mathrm{Mg}$ turnings and $\mathrm{CoBr}_{2}$ in Schlenk tube and heating under vacuum for 5-8 minutes using a heat gun.

In our efforts to form low-oxidation-state active Co species in situ, we commenced our studies by selecting metallic magnesium as reductant, to test its reactivity in the hydrogenation of anthracene (Table 1) ${ }^{18}$ Initially, we selected $\mathrm{CoCl}_{2}$ salt as the catalyst and examined it under various reaction conditions. In the absence of external ligands, the low-cost $\mathrm{CoCl}_{2}$ salt with magnesium as reductant was unable to promote the hydrogenation (entry 1). Screening of ligands showed that 2,2'-bipyridine was inefficient in the hydrogenation (entry 2). Interestingly, Co-catalyzed hydrogenation occurred when using dtbpy as ligand; a product with one reduced aromatic side arm was formed (entry 3), only a trace amount of the two-sidearomatic-reduced product $\mathbf{3 a}$ was detected. We recognized that the ligand could play an important role in promoting hydrogenation with Co. Other ligands such as IPr, dppp, Xantphos, and diamino L1 were inefficient in the promotion of the Co-catalyzed hydrogenation (entries 4-7). N-2,6Diisopropylphenyl-bearing diketimine greatly enhanced the catalytic activity of Co to afford 3a in 59\% yield (entry 8). However, with 2,3-dimethyl-substituted diketimine, a trace amount of product 3a was detected (entry 9). Encouraged by the results, we chose different cobalt salts as catalysts. When using $\mathrm{Co}(\mathrm{acac})_{2}$ salt, no hydrogenation took place (entry 10). To our delight, the salt of $\mathrm{CoBr}_{2}$ exhibited high reactivity; it resulted in catalytic hydrogenation of two side aromatics of anthracene in the formation of product 3a (entry 11). Manganese and zinc could not serve as efficient reductants in Co catalysis (entry 12).

Once we had the optimal hydrogenation conditions with $\mathrm{CoBr}_{2}$ and diketimine ligand in hand, we were curious as to whether well-defined diketimine-ligated Co complexes could serve as precatalysts to promote the hydrogenation of $\mathrm{PAH}$. According to known procedures,${ }^{19}$ we prepared the diketimineligated Co complexes and tested their reactivities in the hydrogenation of anthracene. Briefly, diketimine-ligated Co
Table 1 Studying the effect of metal salts, ligands and reductants on selective hydrogenation of anthracene ${ }^{a}$

\begin{tabular}{|c|c|c|c|c|c|}
\hline & $\begin{array}{c}\text { bpy: } R=A \\
\text { ditbpy: } R=\text { = } B \text { Bu }\end{array}$ & $\begin{array}{c}\mathrm{H}_{2} \\
\text { metal salthigand } \\
(10 \mathrm{~mol} \%)\end{array}$ & & & \\
\hline Entry & Metal salt & Ligand & Reductant & $\begin{array}{l}{[\mathbf{2 a}} \\
\%]\end{array}$ & {$[3 \mathbf{a} \%]$} \\
\hline 1 & $\mathrm{CoCl}_{2}$ & None & $\mathrm{Mg}$ & $\mathrm{nd}^{b}$ & $\mathrm{nd}^{b}$ \\
\hline 2 & $\mathrm{CoCl}_{2}$ & Bpy & $\mathrm{Mg}$ & $\mathrm{nd}^{b}$ & $\mathrm{nd}^{b}$ \\
\hline 3 & $\mathrm{CoCl}_{2}$ & Dtbpy & $\mathrm{Mg}$ & 38 & Trace \\
\hline 4 & $\mathrm{CoCl}_{2}$ & $\mathrm{IPr} \cdot \mathrm{HCl}$ & $\mathrm{Mg}$ & $\mathrm{nd}^{b}$ & $\mathrm{nd}^{b}$ \\
\hline 5 & $\mathrm{CoCl}_{2}$ & Dppp & $\mathrm{Mg}$ & $\mathrm{nd}^{b}$ & $\mathrm{nd}^{b}$ \\
\hline 6 & $\mathrm{CoCl}_{2}$ & Xantphos & $\mathrm{Mg}$ & $\mathrm{nd}^{b}$ & $\mathrm{nd}^{b}$ \\
\hline 7 & $\mathrm{CoCl}_{2}$ & Diamino L1 & $\mathrm{Mg}$ & $\mathrm{nd}^{b}$ & $\mathrm{nd}^{b}$ \\
\hline 8 & $\mathrm{CoCl}_{2}$ & Diketimine & $\mathrm{Mg}$ & 26 & 59 \\
\hline 9 & $\mathrm{CoCl}_{2}$ & Me-diketimine & $\mathrm{Mg}$ & 37 & Trace \\
\hline 10 & $\mathrm{Co}(\mathrm{acac})_{2}$ & Diketimine & $\mathrm{Mg}$ & $\mathrm{nd}^{b}$ & $\mathrm{nd}^{b}$ \\
\hline 11 & $\mathrm{CoBr}_{2}$ & Diketimine & $\mathrm{Mg}$ & $\mathrm{nd}^{b}$ & $90[84]^{c}$ \\
\hline 12 & $\mathrm{CoBr}_{2}$ & Diketimine & $\mathrm{Mn}$ or $\mathrm{Zn}$ & $\mathrm{nd}^{b}$ & $\mathrm{nd}^{b}$ \\
\hline 13 & $\mathrm{CoBr}_{2}$ & No & $\mathrm{Mg}$ & $\mathrm{nd}^{b}$ & $\mathrm{nd}^{b}$ \\
\hline 14 & $\mathrm{CoBr}_{2}$ & Diketimine & No & $\mathrm{nd}^{b}$ & $\mathrm{nd}^{b}$ \\
\hline 15 & $\mathrm{CoBr}_{2}$ & Diketimine & $\mathrm{CH}_{3} \mathrm{Li}$ & $\mathrm{nd}^{b}$ & $\mathrm{nd}^{b}$ \\
\hline 16 & $\mathrm{CoBr}_{2}$ & Diketimine & $\mathrm{NaO}^{t} \mathrm{Bu}$ & $\mathrm{nd}^{b}$ & $\mathrm{nd}^{b}$ \\
\hline 17 & $\mathrm{CoBr}_{2}$ & Diketimine & $\mathrm{NaHBEt}_{3}$ & $\mathrm{nd}^{b}$ & $\mathrm{nd}^{b}$ \\
\hline 18 & $\mathrm{CoBr}_{2}$ & Diketimine & $\mathrm{NaO}^{t} \mathrm{Bu} / \mathrm{HBPin}$ & $\mathrm{nd}^{b}$ & $\mathrm{nd}^{b}$ \\
\hline $19^{d}$ & $\mathrm{CoBr}_{2}$ & Diketimine & $\mathrm{NaO}^{t} \mathrm{Bu} / \mathrm{HBPin}$ & $\mathrm{nd}^{b}$ & $\mathrm{nd}^{b}$ \\
\hline
\end{tabular}

${ }^{a}$ Conditions: $1 \mathrm{a}(0.2 \mathrm{mmol})$, metal salt $(0.02 \mathrm{mmol})$, ligand $(0.02 \mathrm{mmol})$, reductant $(0.4 \mathrm{mmol}), \mathrm{H}_{2}(8 \mathrm{MPa})$, THF $(2 \mathrm{~mL}), 60{ }^{\circ} \mathrm{C}, 48 \mathrm{~h} .{ }^{1} \mathrm{H}$ NMR yields using 1,3,5-trimethoxybenzene as internal standard. ${ }^{b}$ Not detected. ${ }^{c}$ Isolated yield. dppp $=1,3$-bis(diphenylphosphino)propane. Xantphos $=$ 4,5-bis(diphenyl phosphino)-9,9-dimethylxanthene.

${ }^{d}$ Without $\mathrm{H}_{2}$.

complexes were prepared by mixing equimolar anhydrous $\mathrm{CoBr}_{2}$ and diketimine in THF and stirred for $24 \mathrm{~h}$ at room temperature, filtered, washed with hexane, and dried in vacuum. The diketimine-Co complex afforded the product 3a in almost equal conversion to that using $\mathrm{CoBr}_{2} /$ diketimine (Scheme 2). Catalytic hydrogenation of PAHs was carried out by heating $\mathrm{Mg}$ turnings (10 mg, $0.4 \mathrm{mmol}$ ) and $\mathrm{CoBr}_{2}$ (5 mg, 0.02 $\mathrm{mmol}$ ) in a Schlenk tube using a heat gun at around $300{ }^{\circ} \mathrm{C}$ under vacuum for $5 \mathrm{~min}$. The mixture was cooled to room temperature in nitrogen atmosphere, PAH $(0.2 \mathrm{mmol})$, diketimine $(8 \mathrm{mg}, 0.02 \mathrm{mmol})$ and THF $(2.0 \mathrm{~mL})$ were added. The

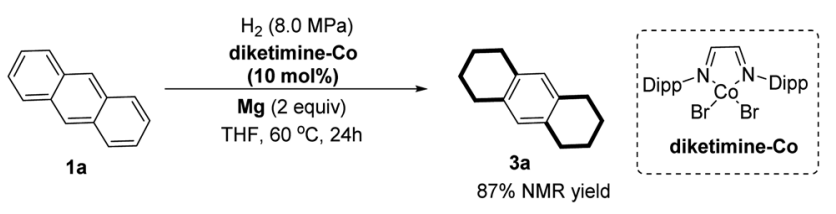

Scheme 2 Testing the catalytic activities of well-defined diketimineCo complexes in hydrogenation of anthracene. 
resulting mixture was heated at $80{ }^{\circ} \mathrm{C}$ for 2 hours. Then the resulting mixture was quickly moved to a high-pressure autoclave. The reaction mixture was stirred under an atmosphere of $\mathrm{H}_{2}$ (8 Mpa) at $60{ }^{\circ} \mathrm{C}$ for $50 \mathrm{~h}$ and then quenched with saturated $\mathrm{NH}_{4} \mathrm{Cl} / \mathrm{H}_{2} \mathrm{O}(4 \mathrm{~mL})$. The crude product was extracted with EtOAc $(3 \times 4 \mathrm{~mL})$. The combined organic phases were dried over anhydrous $\mathrm{Na}_{2} \mathrm{SO}_{4}$ and concentrated under vacuum. After removal of the volatiles under vacuum, the crude products were purified by column chromatography to afford the desired hydrogenation compounds.

With optimal reaction conditions in hand, $\mathrm{CoBr}_{2} /$ diketimine was further used as a precatalyst to explore the scope of Cocatalyzed hydrogenation for the synthesis of two-sidearomatic-reduced motifs (Scheme 3).

1,2,3,4,5,6,7,8-Octahydroanthracene derivatives bearing methyl and substituted phenyl substituents at the C9/C10 positions were prepared by selectively reducing two side carbocycles (3b-31). As expected, the hydrogenation of phenanthrene readily took place with Co catalysis $(\mathbf{3 m})$. When using pyrene, we found that internal carbocycles were reduced to afford 4,5,9,10-tetrahydropyrene (3n). This protocol was extended to the preparation of partially reduced compounds of 1,2,3,4,8,9,10,11-octahydrotetraphene and 1,2,3,10,11,12-hexahydroperylene, by the reduction of related $\mathrm{PAH}$ precursors (3o and $3 \mathbf{s}$ ). It was interesting to note that the hydrogenation of pentacene unexpectedly afforded 1,2,3,4,6,8,9,10,11,13-decahydropentacene $3 \mathbf{p}$ by selective reduction of three carbocycles. A further interesting observation was that four side carbocycles in bianthracene were hydrogenated to form hexadecahydro-9,9'bianthracene (3q). This differs from what was observed in the $\mathrm{Cr}$

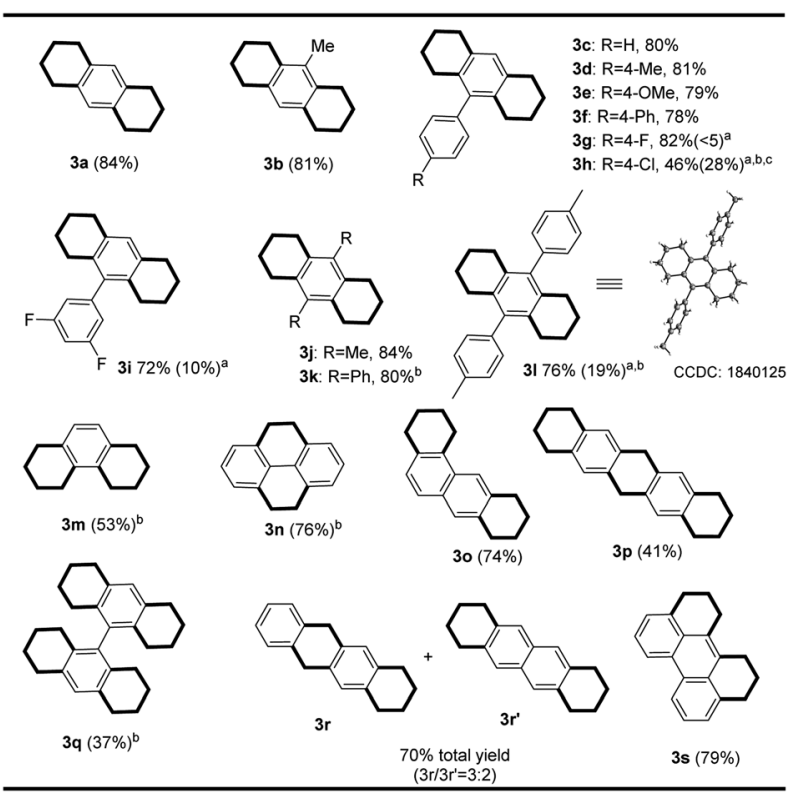

Scheme 3 Co-catalyzed selective hydrogenation of PAHs. PAH (0.2 $\mathrm{mmol}), \mathrm{CoBr}_{2}(0.02 \mathrm{mmol})$, diketimine $(0.02 \mathrm{mmol}), \mathrm{Mg}(0.4 \mathrm{mmol}), \mathrm{H}_{2}$ (8 MPa), THF ( $2 \mathrm{~mL}), 60^{\circ} \mathrm{C}, 48 \mathrm{~h}$. Isolated yields. ${ }^{2}$ Yields of compounds that were formed by reducing one side arenes of PHAs. ${ }^{b} 60 \mathrm{~h} .{ }^{c} \mathrm{Mg}(3.5$ equiv.) was used. catalysis protocol; the formation of a mixed regioisomer (3r and $3 \mathbf{r}^{\prime}$ ) was found in the hydrogenation of tetracene by Co catalysis. This reaction was not tolerable for substrates bearing reducible groups such as $\mathrm{Br}, \mathrm{COOR}, \mathrm{COOH}, \mathrm{CHO}, \mathrm{CN}$ and $\mathrm{NO}_{2}$.

The diketimine-Co-catalyzed hydrogenation protocols can be utilized to reduce substituted olefins (Scheme 4). ${ }^{5,5 d, 7 a, 7 b}$ The double bonds were reduced, with retention of the phenyl and naphthyl groups, affording linear or branched alkylarene motifs in good yields. Moreover, olefin hydrogenation using diketimine-ligated Co complexes took place smoothly (Scheme 5).

To examine whether a low-oxidation-state Co species is formed by the reduction of a $\mathrm{CoBr}_{2}$ salt with magnesium, we performed X-ray photoelectron spectroscopy (XPS) analysis of the oxidation states of $\mathrm{Co}$ in the stoichiometric reactions of $\mathrm{CoBr}_{2}$ with diketimine in the absence or presence of magnesium. Downshift signals with a shift distance of $0.89 \mathrm{eV}$ for the Co $2 \mathrm{p}$ components in the related spectra were observed when conducting the reaction with magnesium in THF (Fig. 1). This shows that low-oxidation-state Co species are formed in situ by the reduction of $\mathrm{CoBr}_{2}$ with magnesium, which then serve as active species to initiate the hydrogenation. The $\pi$-acceptors (arenes, olefins etc.) are able to stabilize low oxidation state reactive metal spices. Previously, it has been reported that Co catalyzed reaction were initiated by the substitution of the labile arenes molecules by $\pi$-acceptor substrates. ${ }^{7 i}$ Jacobi von Wangelin et al. have reported arene-Co and arene-Fe catalysts for hydrogenations of olefins, alkenes, etc. and found that slow hydrogenation of anthracene occurred when there was no suitable $\pi$-acceptor. ${ }^{7 i}$ We also performed controlled experiments of the low-cost $\mathrm{CoBr}_{2}$ salt with magnesium in the absence of diketimine ligand (Table 1, entry 13), but were failed to get hydrogenated anthracene. Additionally, we also checked the Jacobi von Wagelin's arene-M(0) complexes, ${ }^{7 i}$ using anthracene instead of diketimine as ligand for the catalytic hydrogenation of olifens but were unable to get hydrogenated products.

Reaction profiles for the Co-catalyzed hydrogenation of anthracene were investigated. The formation of two-side-

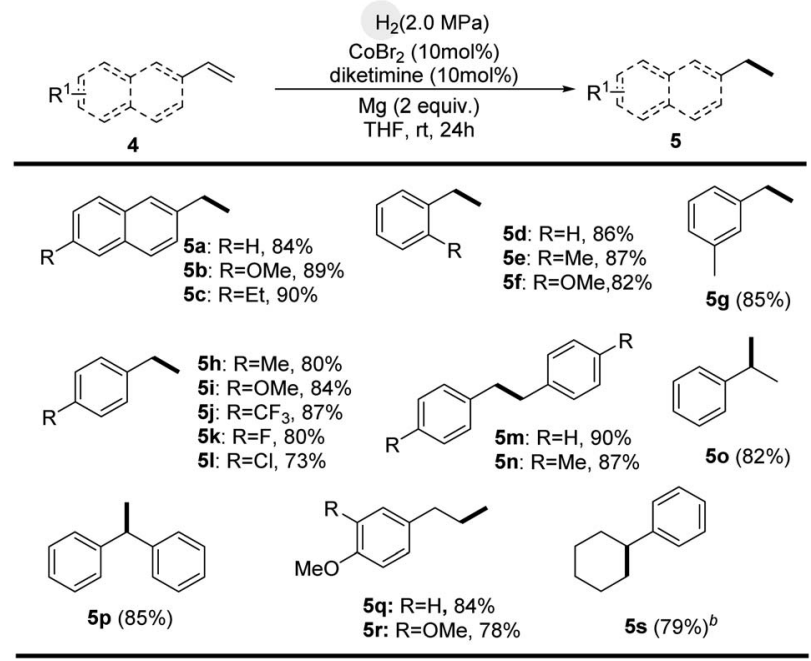

Scheme 4 Diketimine-Co-catalyzed hydrogenation of olefins. 


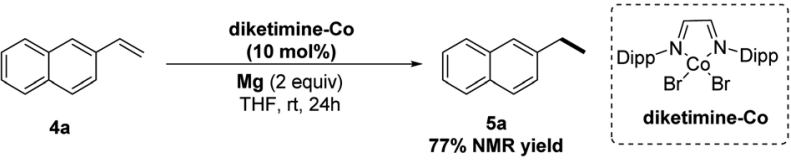

Scheme 5 Testing the catalytic activities of diketimine-Co complexes in hydrogenation of olefins.
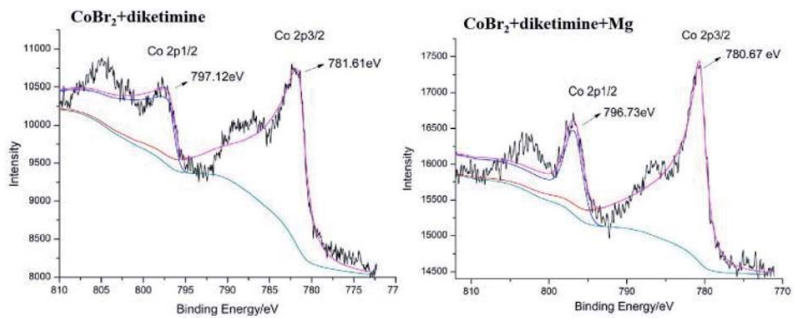

Fig. 1 XPS analysis of stoichiometric reaction mixtures of $\mathrm{CoBr}_{2}$ with diketimine ligand in the absence or presence of metallic magnesium.

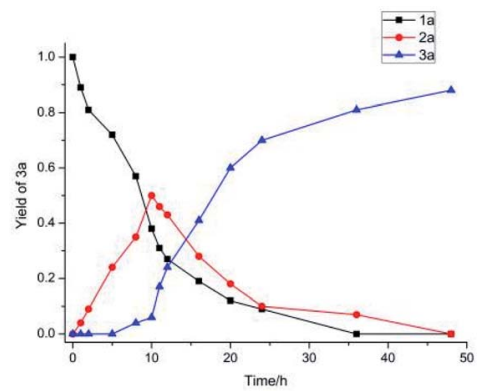

Fig. 2 Reaction profiles for Co-catalyzed hydrogenation of anthracene.

aromatic-reduced product 3a was observed in Co catalysis within the first 10 hours (Fig. 2), and the hydrogenation rate for the conversion of $2 \mathbf{a}$ to $\mathbf{3 a}$ increased.

The scalability of the hydrogenation of anthracene was examined on gram scale. It was found that performing the Cocatalyzed reactions on the scale of $10 \mathrm{mmol}$ did not affect the

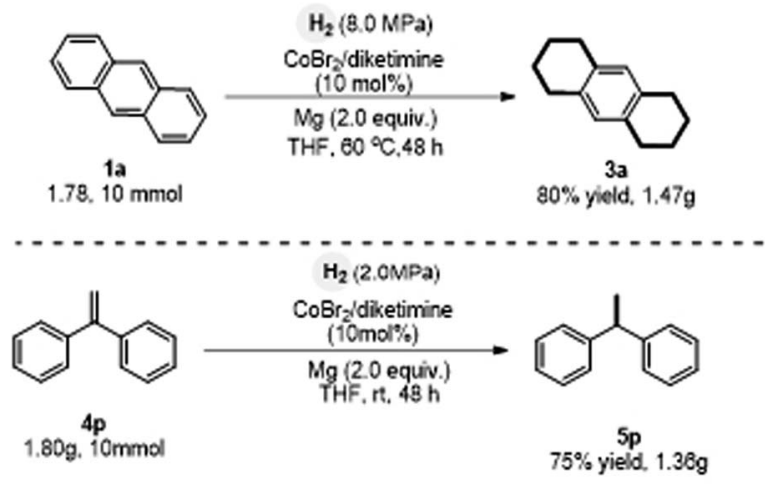

Scheme 6 Gram-scale hydrogenation of $1 \mathrm{a}$ and $4 \mathrm{p}$. efficiency of site-selective hydrogenation, hence permitting the scalable preparation of $3 \mathbf{a}$ and $\mathbf{5 p}$ (Scheme 6).

\section{Conclusions}

In summary, we have developed an economic and site-selective hydrogenation of challenging PAHs with earth-abundant Co catalysis. ${ }^{20}$ arene-Co and arene-Fe catalysts for hydrogenations of olefins, alkenes, ketones, and imines have been previously reported by Jacobi von Wangelin et al. ${ }^{7 i}$ in this study, we used low-cost and commercially available $\mathrm{CoBr}_{2}$ salts as precatalysts combined with diketimine ligand and air-stable magnesium as the reductant for site-selective hydrogenation of two side aromatic hydrocarbons of PAHs and olefins. A wide range of PAHs such as tetracene, tetraphene, perylene, pentacene, and bianthracene were amenable to the hydrogenation, providing a cost-effective and clean strategy for the synthesis of two-sidearomatic-reduced polycyclic hydrocarbon motifs in high site selectivity. The high reactivity of Co catalysis with diketimine ligand indicates that the methodology outlined herein will have potential applications in the hydrogenation of challenging substrates.

\section{Conflicts of interest}

The authors declare no competing financial interests.

\section{Acknowledgements}

We acknowledge financial support from the National Natural Science Foundation of China (22061041), National Natural Science Foundation of Shaanxi Province (2020JQ-789), Open Sharing Platform for Scientific and Technological Resources of Shaanxi Province (2021PT-004), Doctoral Research Foundation of Yan'an University (YDBK2019-60), the Shaanxi Province Training Program of Innovation and Entrepreneurship for Undergraduates (S202010719114) and Research Program of Yan'an University (YDY2020-61).

\section{Notes and references}

1 Catalysis without precious metals, ed. R. M. Bullock, WileyVCH, Hoboken, NJ, 2010.

2 Handbook of Homogeneous Hydrogenation, ed. J. G. de Vries and C. J. Elsevier, Wiley-VCH, Weinheim, 2007.

3 (a) F. Glorius, Asymmetric Hydrogenation of aromatic compounds, Org. Biomol. Chem., 2005, 3, 4171-4175; (b) S. Werkmeister, J. Neumann, K. Junge and M. Beller, Pincer-Type Complexes for Catalytic (De)Hydrogenation and Transfer (De)Hydrogenation Reactions: Recent Progress, Chem.-Eur. J., 2015, 21, 12226-12250; (c) T. Zell and D. Milstein, Hydrogenation and Dehydrogenation Iron Pincer Catalysts Capable of Metal-Ligand Cooperation by Aromatization/Dearomatization, Acc. Chem. Res., 2015, 48, 1979-1994; (d) D. Zhao, L. Candish, D. Paul and F. Glorius, $\mathrm{N}$-Heterocyclic Carbenes in Asymmetric Hydrogenation, ACS Catal., 2016, 6, 5978-5988; (e) J.-H. Xie, S.-F. Zhu and 
Q.-L. Zhou, Transition Metal-Catalyzed Enantioselective Hydrogenation of Enamines and Imines, Chem. Rev., 2011, 111, 1713-1760; (f) Y.-G. Zhou, Asymmetric Hydrogenation of Heteroaromatic Compounds, Acc. Chem. Res., 2007, 40, 1357-1366; $(g)$ W. Tang and X. Zhang, New Chiral Phosphorus Ligands for Enantioselective Hydrogenation, Chem. Rev., 2003, 103, 3029-3070; (h) R. H. Morris, Exploiting Metal-Ligand Bifunctional Reactions in the Design of Iron Asymmetric Hydrogenation Catalysts, Acc. Chem. Res., 2015, 48, 1494-1502; ( $i$ ) D. Zhao and F. Glorius, Angew. Enantioselective Hydrogenation of Isoquinolines, Angew. Chem. Int. Ed., 2013, 52, 9616-9618; (j) S. Werkmeister, K. Junge and M. Beller, Catalytic Hydrogenation of Carboxylic Acid Esters, Amides, and Nitriles with Homogeneous Catalysts, Org. Process Res. Dev., 2014, 18, 289-302; (k) R. Noyori, Asymmetric Catalysis: Science and Opportunities (Nobel Lecture), Angew. Chem., Int. Ed., 2002, 41, 2008-2022.

4 P. J. Chirik, Iron- and Cobalt-Catalyzed Alkene Hydrogenation: Catalysis with Both Redox-Active and Strong Field Ligands, Acc. Chem. Res., 2015, 48, 1687-1695.

5 (a) R. V. Jagadeesh, A.-E. Surkus, H. Junge, M.-M. Pohl, J. Radnik, J. Rabeah, H. Huan, V. Schünemann, A. Brückner and M. Beller, Nanoscale Fe2O3-Based Catalysts for Selective Hydrogenation of Nitroarenes to Anilines, Science, 2013, 342, 1073-1076; (b) J. A. Garg, S. Chakraborty, Y. Ben-David and D. Milstein, Unprecedented Iron-catalyzed Selective Hydrogenation of Activated Amides to Amines and Alcohols, Chem. Commun., 2016, 52, 5285-5288; (c) S. C. Bart, E. Lobkovsky and P. J. Chirik, Preparation and Molecular and Electronic Structures of Iron(0) Dinitrogen and Silane Complexes and Their Application to Catalytic Hydrogenation and Hydrosilation, J. Am. Chem. Soc., 2004, 126, 13794-13807; (d) T. N. Gieshoff, U. Chakraborty, M. Villa and A. Jacobi von Wangelin, Alkene Hydrogenations by Soluble Iron Nanocluster Catalysts, Angew. Chem., Int. Ed., 2017, 56, 3585-3589; (e) S. Fleischer, S. Zhou, K. Junge and M. Beller, General and Highly Efficient Iron-Catalyzed Hydrogenation of Aldehydes, Ketones, and $\alpha, \beta$-Unsaturated Aldehydes, Angew. Chem., Int. Ed., 2013, 52, 5120-5124.

6 (a) N. G. Léonard and P. J. Chirik, Air-Stable $\alpha$-Diimine Nickel Precatalysts for the Hydrogenation of Hindered, Unactivated Alkenes, ACS Catal., 2018, 8, 342-348; (b) X. Li, C. You, S. Li, H. Lv and X. Zhang, Nickel-Catalyzed Enantioselective Hydrogenation of $\beta$-(Acylamino)acrylates: Synthesis of Chiral $\beta$-Amino Acid Derivatives, Org. Lett., 2017, 19, 51305133.

7 Selected examples of Co-catalyzed hydrogenation: (a) D. Gärtner, A. Welther, B. R. Rad, R. Wolf and A. Jacobi von Wangelin, Heteroatom-Free Arene-Cobalt and AreneIron Catalysts for Hydrogenations, Angew. Chem., Int. Ed., 2014, 53, 3722-3726; (b) G. Zhang, B. L. Scott and S. K. Hanson, Mild and Homogeneous Cobalt-Catalyzed Hydrogenation of $\mathrm{C}=\mathrm{C}, \mathrm{C}=\mathrm{O}$, and $\mathrm{C}=\mathrm{N}$ Bonds, Angew. Chem., Int. Ed., 2012, 51, 12102-12106; (c) D. Srimani, A. Mukherjee, A. F. G. Goldberg, G. Leitus, Y. Diskin-
Posner, L. J. W. Shimon, Y. B. David and D. Milstein, Cobalt-Catalyzed Hydrogenation of Esters to Alcohols: Unexpected Reactivity Trend Indicates Ester Enolate Intermediacy, Angew. Chem., Int. Ed., 2015, 54, 1235712360; (d) R. Adam, J. R. Cabrero-Antonino, A. Spannenberg, K. Junge and R. Jackstell, A General and Highly Selective Cobalt-Catalyzed Hydrogenation of $\mathrm{N}$ Heteroarenes under Mild Reaction Conditions, Angew. Chem., Int. Ed., 2017, 56, 3216-3220; (e) M. R. Friedfeld, M. Shevlin, G. W. Margulieux, L.-C. Campeau and P. J. Chirik, Cobalt-Catalyzed Enantioselective Hydrogenation of Minimally Functionalized Alkenes: Isotopic Labeling Provides Insight into the Origin of Stereoselectivity and Alkene Insertion Preferences, J. Am. Chem. Soc., 2016, 138, 3314-3324; $(f)$ A. Mukherjee, D. Srimani, S. Chakraborty, Y. Ben-David and D. Milstein, Selective Hydrogenation of Nitriles to Primary Amines Catalyzed by a Cobalt Pincer Complex, J. Am. Chem. Soc., 2015， 137，8888-8891; ( $g$ ) R. Adam, C. B. Bheeter, J. R. Cabrero-Antonino, K. Junge, R. Jackstell and M. Beller, Selective Hydrogenation of Nitriles to Primary Amines by using a Cobalt Phosphine Catalyst, ChemSusChem, 2017, 10, 842-846; (h) M. R. Friedfeld, G. W. Margulieux, B. A. Schaefer and P. J. Chirik, Bis(phosphine)cobalt Dialkyl Complexes for Directed Catalytic Alkene Hydrogenation, J. Am. Chem. Soc., 2014, 136, 13178-13181; (i) P. Büschelberger, D. Gärtner, E. Reyes-Rodriguez, F. Kreyenschmidt, K. Koszinowski, A. Jacobi von Wangelin and R. Wolf, Chem.-Eur. J., 2017, 23, 3139-3151.

8 (a) Y.-Q. Zou, S. Chakraborty, A. Nerush, D. Oren, Y. DiskinPosner, Y. Ben-David and D. Milstein, Highly Selective, Efficient Deoxygenative Hydrogenation of Amides Catalyzed by a Manganese Pincer Complex via Metal-Ligand Cooperation, ACS Catal., 2018, 8, 8014-8019; (b) F. Kallmeier, T. Irrgang, T. Dietel and R. Kempe, Highly Active and Selective Manganese $\mathrm{C}=\mathrm{O}$ Bond Hydrogenation Catalysts: The Importance of the Multidentate Ligand, the Ancillary Ligands, and the Oxidation State, Angew. Chem., Int. Ed., 2016, 55, 11806-11809; (c) R. van Putten, E. A. Uslamin, M. Garbe, C. Liu, A. Gonzalez-de-Castro, M. Lutz, K. Junge, E. J. M. Hensen, M. Beller, L. Lefort and E. A. Pidko, Non-Pincer-Type Manganese Complexes as Efficient Catalysts for the Hydrogenation of Esters, Angew. Chem., Int. Ed., 2017, 56, 7531-7534.

9 (a) W. Liu, B. Sahoo, K. Junge and M. Beller, Cobalt Complexes as an Emerging Class of Catalysts for Homogeneous Hydrogenations, Acc. Chem. Res., 2018, 51, 1858-1869; (b) M. D. Greenhalgh, A. S. Jones and S. P. Thomas, Iron-Catalysed Hydrofunctionalisation of Alkenes and Alkynes, ChemCatChem, 2015, 7, 190-222.

10 Selected examples of hydrogenation of arenes: (a) M. P. Wiesenfeldt, Z. Nairoukh, W. Li and F. Glorius, Hydrogenation of fluoroarenes: Direct access to all-cis(multi)fluorinated cycloalkanes, Science, 2017, 357, 908912; (b) M. P. Wiesenfeldt, T. Knecht, C. Schlepphorst and F. Glorius, Silylarene Hydrogenation: A Strategic Approach that Enables Direct Access to Versatile Silylated Saturated 
Carbo- and Heterocycles, Angew. Chem., Int. Ed., 2018, 57, 8297-8300; (c) Y. Wei, B. Rao, X. Cong and X. Zeng, Highly Selective Hydrogenation of Aromatic Ketones and Phenols Enabled by Cyclic (Amino)(alkyl)carbene Rhodium Complexes, J. Am. Chem. Soc., 2015, 137, 9250-9253; (d) R. Kuwano, R. Morioka, M. Kashiwabara and N. Kameyama, Catalytic Asymmetric Hydrogenation of Naphthalenes, Angew. Chem., Int. Ed., 2012, 51, 4136-4139.

11 (a) S.-C. Qi, X.-Y. Wei, Z.-M. Zong and Y.-K. Wang, Application of Supported Metallic Catalysts in Catalytic Hydrogenation of Arenes, RSC Adv., 2013, 3, 14219-14232; (b) A. Gual, C. Godard, S. Castilloń and C. Claver, Soluble Transition-Metal Nanoparticles-Catalysed Hydrogenation of Arenes, Dalton Trans., 2010, 39, 11499-11512.

12 (a) J.-i. Ito, K. Sugino, S. Matsushima, H. Sakaguchi, H. Iwata, T. Ishihara and H. Nishiyama, Synthesis of NHCOxazoline Pincer Complexes of $\mathrm{Rh}$ and $\mathrm{Ru}$ and Their Catalytic Activity for Hydrogenation and Conjugate Reduction, Organometallics, 2016, 35, 1885-1894; (b) H. B. Pan and C. M. Wai, Facile Sonochemical Synthesis of Carbon Nanotube-Supported Bimetallic Pt-Rh Nanoparticles for Room Temperature Hydrogenation of Arenes, New J. Chem., 2011, 35, 1649-1660; (c) M. Fang and R. A. Sánchez-Delgado, Ruthenium Nanoparticles Supported on Magnesium Oxide: A Versatile and Recyclable Dual-site Catalyst for Hydrogenation of Monoand Poly-cyclic Arenes, N-heteroaromatics, and Sheteroaromatics, J. Catal., 2014, 311, 357-368; (d) C. Hubert, E. G. Bilé, A. Denicourt-Nowicki and A. Roucoux, $\mathrm{Rh}(0)$ Colloids Supported on TiO2: A Highly Active and Pertinent Tandem in Neat Water for the Hydrogenation of Aromatics, Green Chem., 2011, 13, 17661771.

13 (a) J. H. Docherty, J. Peng, A. P. Dominey and S. P. Thomas, Activation and Discovery of Earth-Abundant Metal Catalysts Using Sodium tert-butoxide, Nat. Chem., 2017, 9, 595-600; (b) M. D. Greenhalgh, D. J. Frank and S. P. Thomas, Iron-
Catalysed Chemo-, Regio-, and Stereoselective Hydrosilylation of Alkenes and Alkynes using a BenchStable Iron(II) Pre-Catalyst, Adv. Synth. Catal., 2014, 356, 584-590.

14 K. Gao and N. Yoshikai, Low-Valent Cobalt Catalysis: New Opportunities for C-H Functionalization, Acc. Chem. Res., 2014, 47, 1208-1219.

15 S. Friedman, S. Metlin, A. Svedi and I. Wender, Selective Hydrogenation of Polynuclear Aromatic Hydrocarbons, J. Org. Chem., 1959, 24, 1287-1289.

16 (a) F. Nador, Y. Moglie, C. Vitale, M. Yus, F. Alonso and G. Radivoy, Reduction of Polycyclic Aromatic Hydrocarbons Promoted by Cobalt or Manganese Nanoparticles, Tetrahedron, 2010, 66, 4318-4325; (b) E. Nelkenbaum, I. Dror and B. Berkowitz, Reductive Hydrogenation of Polycyclic Aromatic Hydrocarbons Catalyzed by Metalloporphyrins, Chemosphere, 2007, 68, 210-217.

17 B. Han, P. Ma, X. Cong, H. Chen and X. Zeng, Chromiumand Cobalt-Catalyzed, Regiocontrolled Hydrogenation of Polycyclic Aromatic Hydrocarbons: A Combined Experimental and Theoretical Study, J. Am. Chem. Soc., 2019, 141, 9018-9026.

18 M. T. Mock, S. Chen, M. O'Hagan, R. Rousseau, W. G. Dougherty, W. S. Kassel and R. M. Bullock, Dinitrogen Reduction by a Chromium(0) Complex Supported by a 16-Membered Phosphorus Macrocycle, J. Am. Chem. Soc., 2013, 135, 11493-11496.

19 T. V. Laine, M. Klinga, A. Maaninen, E. Aitola and M. Leskelä, Effect of Metal on the Ethylene Polymerization Behavior of a Diimine-Based Homogeneous Late Transition Metal Catalyst System, Acta Chem. Scand., 1999, 53, 968-973.

20 J. Schneidewind, R. Adam, W. Baumann, R. Jackstell and M. Beller, Low-Temperature Hydrogenation of Carbon Dioxide to Methanol with a Homogeneous Cobalt Catalyst, Angew. Chem., Int. Ed., 2017, 56, 1890-1893. 